\title{
Carta ao Editor
}

\section{Esta esquecida força eletromotriz de movimento}

Está nas livrarias a sétima edição em português do prestigioso Halliday \& Resnick [1], certamente o texto de física geral mais usado por estudantes de ciências e de engenharia no Brasil. É curioso constatar que o livro mantém esta posição apesar das inúmeras críticas que recebe tanto de professores como de estudantes, críticas essas que se avolumam a cada nova edição. De fato, creio que poucos usuários antigos discordariam da afirmação de que a obra atingiu uma espécie de ápice na quarta edição brasileira [2], a última com apenas dois autores, passando a perder qualidade a partir daí.

Deixemos de lado os conhecidos vícios de tradução, as confusões de sistemas de unidades, os problemas mal propostos ou com resposta errada. Há questões de fundo a serem discutidas. Proponho discutir aqui uma questão que diz respeito à explicação de uma determinada classe de fenômenos relacionados com a indução eletromagnética, a qual, salvo melhor juízo, vem sendo abordada de maneira equivocada pelos autores desde a primeira edição original [3]. Na impossibilidade de uma análise detalhada das sucessivas edições, tentarei esclarecer o assunto comparando brevemente as três edições mencionadas acima.

A questão que proponho refere-se à força eletromotriz induzida em um objeto metálico que se move sujeito a um campo magnético uniforme e estacionário, em determinadas situações como, por exemplo, quando um simples bastão metálico se move perpendicularmente a si próprio e ao campo magnético, ou no caso de um dínamo de disco de Faraday, também conhecido como gerador homopolar. A abordagem equivocada consiste em forçar a explicação do fenômeno, nessas situações, com base na lei de Faraday. Esta lei estabelece que a força eletromotriz induzida em um circuito vale a variação temporal do fluxo magnético através da área por ele delimitada. Ora, nas situações mencionadas, não se configura a existência de um circuito fechado bem definido e, portanto, não há uma área bem definida através da qual se possa calcular o fluxo. Força-se, então, a aplicação da lei de Faraday, mediante o uso de artifícios tais como criar circuitos imaginários ou considerar "áreas varridas", ou seja, mediante a introdução de elementos estranhos ao conteúdo original da referida lei. O preço que se paga é esconder a verdadeira origem física do fenômeno, que é, essencialmente, de natureza magnetostática.

$\mathrm{Na}$ primeira edição original [3], os autores tratam inicialmente uma situação em que a lei de Faraday se aplica: uma espira retangular de largura $\ell$ sendo retirada com velocidade $\mathbf{v}$ de uma região onde atua um campo magnético uniforme e estacionário $\mathbf{B}$, de tal forma que a força eletromotriz induzida resulta $\varepsilon=B \ell v$ (cap. 35, seção 4, p. 744; considero desnecessário descrever mais precisamente a situação, pois ela é bastante conhecida e encontrável em vários textos do mesmo nível). Informam, inclusive, que o fenômeno denominase força eletromotriz de movimento (motional emf). Mas, na seção seguinte, intitulada justamente motional emf e, portanto, destinada a esclarecer o assunto, começam dizendo: "vimos que, se um condutor de comprimento $\ell$ é puxado através de um campo uniforme $\mathbf{B}$ com velocidade $\mathbf{v}$, aparece uma fem de movimento $\varepsilon$ dada por $\varepsilon=B \ell v$, se $\ell, \mathbf{B}$ e $\mathbf{v}$ são mutuamente perpendiculares". Ora, existe aí uma desconexão lógica inaceitável. O que foi visto antes é que surge uma fem $\varepsilon=B \ell v$ na espira como um todo, em decorrência da variação de fluxo através da sua área, sendo que

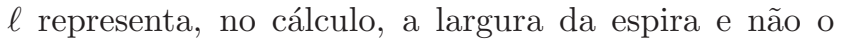
comprimento de um de seus lados em particular. Ou seja, o resultado do cálculo de $\varepsilon$ para uma dada situação é transposto, de maneira simplista, para outra situação completamente diversa. Mas, logo após este atropelo, esclarecem que os portadores de carga $q$ dentro da espira sofrem uma força magnética $\mathbf{F}=q \mathbf{v} \times \mathbf{B}$, sendo a fem induzida representada basicamente pelo trabalho dessa força sobre eles: $\varepsilon=\frac{1}{q} \oint \vec{F} \cdot d \vec{\ell}$, sendo a integral de linha calculada ao longo de toda a espira. Demonstra-se, então, que a única contribuição não nula para a integral vem do percurso ao longo do lado de comprimento $\ell$ que se move dentro do campo e resulta em $\varepsilon=B \ell v$, de sorte que a afirmação inicial fica justificada. "A fem de movimento é intimamente conectada com a deflexão lateral de uma partícula carregada que se move em um campo magnético", concluem os autores.

Em seguida, tratam do caso de uma haste que gira presa por uma de suas extremidades sobre um plano perpendicular a um campo magnético uniforme e estacionário, varrendo um círculo de raio igual ao seu comprimento. Apresentam duas soluções. A primeira solução parte da expressão $\varepsilon=B \ell v$, que os autores elevam à categoria de uma "fórmula feita": subdivide-se a haste em porções infinitesimais de comprimento $d \ell$, ficando cada uma das porções sujeita a uma fem $d \varepsilon=B v d \ell$. A segunda solução considera um setor circular imaginário cuja área cresce à medida que a haste gira e trata-o 
como se fosse de fato um circuito fechado, aplicando a ele a lei de Faraday. Eis aí o nascedouro dos "circuitos imaginários" e das "áreas varridas"... A solução mais óbvia, mais simples e plena de significado físico não é apresentada: seria calcular a fem com base no trabalho realizado pela força magnética sobre os portadores de carga ao deslocá-los de uma extremidade até a outra da haste.

O caso de gerador homopolar aparece como problema proposto ao final do capitulo (problema 10, p. 761). Não faço idéia sobre que artifícios sugeririam os autores para resolvê-lo sem considerar o trabalho da força magnetostática sobre os portadores de carga. Pelo que se infere a partir da estrutura lógica do texto, é lícito pensar que sugeririam considerar-se o disco como feito pela justaposição de setores circulares de abertura angular infinitesimal, comportando-se cada setor como uma haste.

Em resumo, pode-se, com boa vontade, considerar satisfatório o tratamento dado ao fenômeno força eletromotriz de movimento nesta primeira edição original do Halliday \& Resnick, apesar de os autores privilegiarem uma explicação macroscópica baseada na lei de Faraday, em detrimento da explicação microscópica que evidencia a origem eminentemente magnetostática da fem "induzida". Numa tentativa de compreender esta prevalência, arrisco dizer que decorre de uma percepção equivocada da estrutura conceitual da teoria eletromagnética: sendo a lei de Faraday uma das quatro equações fundamentais do eletromagnetismo, devemos nos esforçar para extrair dela (bem como das outras três, é claro) a explicação de todos os fenômenos eletromagnéticos...

A última edição brasileira com dois autores ([2]) é tradução da terceira edição americana. Inicia como a primeira edição original, mas logo surgem alterações importantes. Não há mais uma seção específica denominada força eletromotriz de movimento e não mais se menciona a força magnética sobre os portadores de carga. Os autores ensinam a usar a "fórmula feita" $\varepsilon=B l v$ sem justificá-la devidamente, prometendo explicar mais adiante por que se pode considerar a fem como localizada no lado da espira retangular cujo comprimento é $\ell$ e que se move dentro do campo (p. 224, último parágrafo). A explicação vem no final do capítulo, em uma seção de leitura opcional denominada indução e movimento relativo. Trata-se de uma seção de leitura difícil e sujeita a críticas do ponto de vista conceitual, pois propõe que se veja o fenômeno a partir de diferentes referenciais inerciais. Ora, sabe-se que, em se tratando de fenômenos eletromagnéticos, não se pode mudar de referencial à moda Galileu. Em dado ponto, para acomodar as coisas, os autores afirmam que um observador em um referencial em repouso em relação à espira deve postular a existência de um campo elétrico neste referencial. Mas, sabemos, não se trata de postular, e sim de transformar o campo eletromagnético de um referencial inercial para outro e a transformação não é tão simples como lá é apresentada. Mesmo assim, a força magnética sobre os portadores de carga volta a ser mencionada nesta seção e um leitor atento e criterioso poderá apreender o essencial. No entanto, como a maioria dos estudantes de ciências e engenharia não lêem esta seção, nossos cientistas e engenheiros ficam sem saber qual é, em última instância, o fenômeno físico responsável pela geração da imensa maior parte da energia elétrica que utilizamos. É curioso notar que a expressão fem de movimento é mencionada no texto, mas não aparece no índice remissivo da obra. Seria um ato falho? Em suma, já não é possível considerar satisfatório o tratamento dado ao fenômeno fem de movimento nesta edição.

Pelo acima exposto, percebe-se uma dificuldade atávica dos autores para com a fem de movimento. Nesta recente sétima edição brasileira [1], que é tradução da sétima edição americana, eles resolvem sua dificuldade de maneira sumária: ignoram o fenômeno, varrem-no do universo dos fenômenos físicos. Não há em todo o livro, nem no texto, nem nas perguntas, nem nos problemas, nem no índice remissivo qualquer menção à expressão fem de movimento. Todas as situações físicas do tipo das que discutimos até aqui, nas quais não se configura a existência de um circuito elétrico fechado bem definido, foram banidas. O mundo é feito de espiras e bobinas. Até o gerador homopolar, que havia sido esquecido entre os problemas propostos em uma edição anterior, foi agora diligentemente removido. Mas, mais do que ignorar uma importante gama de fenômenos físicos, os autores negam a sua existência, pois afirmam peremptoriamente que tanto faz quem se move, se o ímã que gera o campo ou a espira que sofre o fluxo. Na página 259, no quarto parágrafo, escrevem: "É verdade que (num caso) o fluxo está variando porque B está variando e (no outro caso) o fluxo está variando porque a parte da espira que está imersa no campo magnético está variando, mas esta diferença não é importante". Ora, se esta diferença não é importante, de onde surgiu então a relatividade restrita? E porque os próprios autores houveram por bem incluir em edições anteriores a já mencionada e criticada e agora excluída seção sobre indução e movimento relativo?

Concentremos um pouco nossa atenção sobre a lei de Faraday. Uma belíssima apreciação a respeito dela aparece nas Feynman Lectures on Physiscs [5], que me permito citar no original:

So the 'flux rule' - that the emf in a circuit is equal to the rate of change of the magnetic flux through the circuit - applies whether the flux changes because the field changes or because the circuit moves (or both). The two possibilities - 'circuit moves' or 'field changes' are not distinguished in the statement of the rule. Yet in our ex- 
planation of the rule we have used two completely distinct laws for the two cases $-\mathbf{v} \times \mathbf{B}$ for 'circuit moves' and $\nabla \times \mathbf{E}=-\partial \mathbf{B} / \partial$ t for 'field changes'.

We know of no other place in physics where such a simple and accurate general principle requires for its real understanding an analysis in terms of two different phenomena (grifado no original). (...). We have to understand the 'rule' as the combined effects of two separate phenomena.

We must look at the 'flux rule' in the following way. In general, the force per unit charge is $\mathbf{F} / \mathrm{q}=\mathbf{E}+\mathbf{v} \times \mathbf{B}$. In moving wires there is the force from the second term. Also, there is an E-field if there is somewhere a changing magnetic field. They are independent effects, but the emf around the loop of wire is always equal to the rate of change of the magnetic flux through it."

Vê-se, aí, que a "regra do fluxo" pode ser aplicada a casos de força eletromotriz de movimento, desde que haja um "loop of wire" através do qual calcular o fluxo, como é o caso mais comum dos geradores de corrente alternada. Se não houver "loop of wire", como no caso do gerador homopolar, fica apenas a alternativa $\mathbf{F}=q \mathbf{v} \times \mathbf{B}$. Note-se que Feynman minimiza a importância da lei de Faraday, conforme apresentada nos livros de física geral, ao chamá-la, simplesmente, de "regra do fluxo". Outra observação digna de nota: quando a "regra do fluxo" é guindada à condição de uma das equações de Maxwell sob o nome de lei de Faraday, não leva consigo essa versatilidade em descrever duas classes de fenômenos. Lá, ela se especializa em descrever os campos elétricos induzidos por campos magnéticos não estacionários.
Nunca é demais ressaltar que as quatro equações de Maxwell não bastam para descrever completamente os fenômenos eletromagnéticos. Elas relacionam os campos com suas fontes, mas é preciso ainda dizer como os campos agem. A ação dos campos sobre a matéria é formalmente expressa pela relação chamada de força de Lorentz, $\mathbf{F}=q(\mathbf{E}+\mathbf{v} \times \mathbf{B})$, que, assim, completa as equações de Maxwell. A lei de Faraday, na forma como integra o conjunto das equações de Maxwell, tem a ver com a indução de campos elétricos por campos magnéticos não estacionários. A fem de movimento tem a ver com uma parte da força de Lorentz, pois decorre da ação de um campo magnético sobre portadores de carga elétrica. E a regra de Faraday $\varepsilon=-d \phi_{B} / d t$ tem a ver com ambas as coisas. Por isso, não se pode dedicar um capítulo ou uma aula ao estudo da regra de Faraday sem falar dessas duas coisas.

Paulo Henrique Dionisio E-mail: phdionisio@uol.com.br

\section{Referências}

[1] Este artigo refere-se mais especificamente ao terceiro volume da série: D. Halliday, R. Resnick e J. Walker, Fundamentos de Física - Eletromagnetismo (LTC, Rio de Janeiro, 2007), v. 3.

[2] D. Halliday e R. Resnick, Física (LTC, Rio de Janeiro, 1985).

[3] D. Halliday e R. Resnick, Physics for Students of Science and Engineering (Wiley, Nova York e Londres, 1960).

[4] Ver, por exemplo, P. Lorrain e D.R. Corson. Eletromagnetic Fields and Waves (Freeman, San Francisco, 1970), p. 261.

[5] R.P. Feynman, R.B. Leighton e M Sands, The Feynman Lectures on Physics (Addison-Wesley, Reading, Massachussetts, 1977) v. 2, cap. 17, p. 17-2. 